\title{
Disclosure, Hidden Charges and Indexed Pensions
}

\author{
Diana Beal, Sarath Delpachitra and Bruce Grundy
}

$\mathrm{I}$

n 1989, the Australian Government released a retirement incomes policy designed to overcome a future federal budget problem caused by an ageing population, an increasing dependency ratio, a poor savings history and a low savings ethic within the community. The dependency ratio, the proportion of people aged 65 years and over to the working age (15-64 years) population, was 16.4 per cent in 1989 (Foster, 1996) but has been projected to increase in line with population ageing from 18.0 per cent in 2000 to 32.2 per cent in 2030 and 37.5 per cent in 2050 (Kelly and Harding, 2004).

The Australian community's assessment of the retirement incomes policy has not been one of universal acclaim. While many people see the wisdom of saving and investing to secure comfortable retirement incomes, others do not support the system and complain (among other issues) that they could use their compulsorycontribution funds more satisfactorily earlier in their lives, that the superannuation system is too complex, too many changes are made and that fees and charges are too high. Nevertheless, the value of funds managed within the superannuation system has increased dramatically. From a base of less than $\$ 100$ billion in 1988 (Foster, 1996), superannuation funds managed both within and outside life insurance offices have grown 12.4 per cent annually to just under $\$ 650$ billion at the end of September 2004 (APRA, 2005).

The Australian Government has taken the issue of fees and the disclosure of those fees seriously. For an industry of this size, fees of one or two per cent per annum have the ability to generate enormous revenue for funds managers. However, fees have not been the only issue of interest to legislators and regulators. The Government instituted a law reform program which included extensive reform of the financial services industry and eventually the passing of the Financial Services Reform Act 2001 (FSRA) which inserted a new Chapter 7 in the Corporations Act 2001. The essential feature of the FSRA is the requirement for more extensive disclosure of product characteristics including fees, of the suppliers of products and of advisers and their alliances. Disclosure takes the form of product disclosure statements (PDSs) to describe products, financial services guides (FSGs) to inform clients of services offered and statements of advice (SAs) to document actual advice offered to individual clients. PDSs are required for superannuation, investment life insurance and other managed fund products. FSRA guidance was followed up by the issue by the regulator, the Australian Securities and Investments Commission (ASIC), in 2001 of Policy

Diana Beal is Associate Professor in Finance, University of Southern Queensland, Sarath Delpachitra is Senior Lecturer in Finance, University of Southern Queensland and Bruce Grundy is Ian Potter Professor, Melbourne Business School. 
Statement (PS) 168: Disclosure: Product Disclosure Statements (and other disclosure obligations) and in 2003 of PS 175 which gives further advice on remuneration disclosure.

This paper analyses the cash flows of lifetime indexed pensions. We conclude that, in practice, the difference between the amount paid for the pension and the present value of the expected future pension income is huge when expectations are based on current mortality tables - around 30 per cent of the amount paid for the pension. With most products, the funds-management industry takes clients' funds, invests to the best of its ability and charges fees for those management services. Risk is borne by the clients. Lifetime indexed pensions are an exceptional product, where the sellers of the pension bear more aspects of risk. Naturally, there must be a payment or reward for bearing risk, but the size of that reward vis$a$-vis the incidence of risk is open to question. More importantly the potential reward is, at present, substantially undisclosed. The next section of the paper describes lifetime indexed pensions and reports a small market survey conducted by the authors and the subsequent section analyses the cash flows. The following section considers some possible rationalizations of the undisclosed 'fees' and the final section discusses policy issues and proposes minimal disclosure requirements.

\section{Lifetime Indexed Pensions}

Indexed pensions are income streams indexed to inflation. Thus, the periodic payments are increased in line with changes in the price level, so that recipients are able to enjoy a standard of living that may be maintained at a reasonably stable level. These income streams are supplied with various options and purchasers may design their income streams to suit their personal circumstances. Options include a fixed term, life expectancy or lifetime duration, single life or reversionary (payments default to a named beneficiary such as a partner on the death of the purchaser), commutation of lump sums possible or not, residual values available or not, guaranteed payment period or not (with lifetime pensions), a selection of payment frequencies (for example, monthly, quarterly or annually) and indexation to the CPI values or to a client-selected value within a given range.

Even though the Government has established incentives to encourage retirees to take income streams rather than lump sums, indexed pensions have not been a popular product. However, the operation of the reasonable benefit limits (RBLs) for taxation concessions on superannuation benefits and the application of the assets test for age-pension means-testing purposes have both dictated roles that complying products can fulfil. A complying pension is one that meets the standards set out in the Superannuation Industry Supervision Act 1993 and Regulations. Basically, compliance means that the income stream is payable for life or life expectancy, there is no residual capital value, commutations are not possible except in very specific circumstances and the income stream cannot be used as security for borrowings. It is obvious that the latter three of these conditions have been imposed to prevent people from converting income streams 
back into lump sums and thus thwarting the RBL system. Similar conditions apply to assets-test exempt income streams.

The RBLs on superannuation benefits are indexed to average weekly ordinary-time earnings and new values are announced each year. In 2004-05, the lump-sum RBL is just under $\$ 620000$ and the pension RBL roughly double that amount. Retirees with more than $\$ 620000$ of assessable benefits may escape the imposition of the highest marginal rate of tax (48.5 per cent) on the excess benefit if they take at least 50 per cent of their total benefits in the form of a complying pension.

For social-security assessment purposes, complying pensions have had a zero assessment value under the assets test, but new complying pensions purchased after 20 September 2004 qualify for a only 50 per cent exemption (Treasurer, 2004). In return for this more onerous treatment of these assets, the government allowed the industry to introduce market-linked complying pensions, which promise to pay higher returns. This concession in regard to the assets test has meant that people with high assets and a desire to access the age pension (possibly for the ancillary heath-care benefits) could purchase a complying income stream, reduce their assessed assets and qualify for a part-pension.

Table 1: Selected Pension Characteristics and the Bearing of Risk

\begin{tabular}{c|ll}
\hline Issue & Option & Risk-bearer \\
\hline \multirow{2}{*}{ Term } & Fixed & Client \\
& Life expectancy & Client \\
& Lifetime & Supplier \\
\hline Guaranteed payment & Yes & Supplier \\
period & No & Client \\
\hline \multirow{2}{*}{ Indexation base } & CPI & Supplier \\
& Client-selected absolute value & Client \\
\hline \multirow{2}{*}{ Viability and safety } & Viability (profitability) & Supplier \\
& Safety for pensioner & Client \\
\hline
\end{tabular}

Note 1: Where clients are forced to select an absolute indexation value, such as 4 per cent, they bear the inflation risk relative to CPI.

The reason that this suite of products has been relatively unpopular stems from the view by retirees that they do not pay well. In arguing for reform in the retirement-income-streams market, the Investment and Financial Services Association (IFSA, 2004) noted that the greatest disadvantage of the preSeptember 2004 complying products is their lack of transparency and disclosure. 
These products are priced in such a way that clients are given a quote for the first year's payment (or payments if paid more frequently than annually). Fees are deducted at the outset and annual fees are taken into account initially as well. Fee structures will be considered in greater detail later in this paper.

Inspection of the various pension options reveals that the selected design of each product has an impact on the risk structure for both the supplier and the client. Table 1 illustrates how risk varies with some pension characteristics. (Some characteristics such as frequency of payments have no bearing on risk, but merely change the variables underlying payment calculations.)

\section{Market Survey and Quotations Received}

In order to evaluate the costs of purchasing an indexed pension, a small market survey was carried out to analyse products offered by different companies. The risk structure of selected products can be expected to have an impact on price. However, in order to simplify the discussion, a 'plain vanilla' design was chosen and priced in the market. The client who proposed the annuity to the various suppliers was assumed to be a 60 -year old female with $\$ 500,000$ to invest in this single-life lifetime pension. She required the income to be paid to her quarterly and indexed to inflation. Only one of the suppliers would quote on an 'indexedto-inflation' basis; the other two required their clients to select an inflationcompensation factor and thereby bear the risk of future price increases relative to CPI. The inflation-compensation or uplift factor was selected at three per cent, so that each year the annual payments would be three per cent higher than those the year before.

The expected term of this lifetime income stream is taken to be 25 years, as such a person has just over 24 years to live, according to the Australian Government Actuary's life expectancy tables. Further, in keeping with the simple model, the income stream was proposed with no guaranteed payment period. A pension with a guaranteed payment period of 10 years, for example, is paid for the equivalent of 10 years even if the recipient dies before the end of that period. The payments for the remainder of the period after death and up to 10 years are paid to the pensioner's estate. The effect of the no-guarantee condition is that the periodic payments should be a little higher, as the supplier can work with a full distribution of terms for the pool of like products. Some annuitants will live a shorter period, in which case the supplier will earn extra profits, as there are no refunds or returns of residual balances, but others will live longer than their current life expectancies, and suppliers of these income streams will bear extra costs.

The websites of 10 of the largest financial institutions in Australia, including seven banks and three insurance companies, were searched for public offers of lifetime indexed pensions. Seven of these institutions were unable to supply quotes, because they apparently did not offer the product, only offered the product via financial planners or would only supply products with maximum terms of 15 years. Quotations were thus obtained from three banking/insurance conglomerates. Table 2 gives details of the quotations received for the first year (2004-2005) of 
the income streams. The annual payments quoted are fourfold multiples of the quarterly payments, not future values.

Table 2: Quotations for Lifetime Income Streams for 60-Year Old Female

\begin{tabular}{c|ccc}
\hline Supplier & Quarterly Payment (\$) & Annual Payment (\$) & Indexation \\
\hline A & 5,110 & 20,440 & $3 \%$ \\
B & 5,277 & 21,108 & CPI \\
C & 5,674 & 22,697 & $3 \%$ \\
\hline
\end{tabular}

\section{Analysis of Cash Flows}

In order to analyse the cash flows which may arise over the full term of such a product and highlight the fees being charged, the following methodology was used. Assume an annual pension is purchased at a cost of $C$. The payment at the end of the first year is $P$ and the payment will grow by a fixed percentage $i$ each year that the pensioner survives. The fee charged is [C - Present value (PV) of the life-time pension income payments]. Equation 1 gives the fee.

$$
\text { Fee }=C-\sum_{t=1}^{M a x-A} \frac{\text { Probability }(\text { Pension recipient lives until } A+t) P(1+i)^{t}}{(1+r)^{t}},
$$

where: $M a x=$ maximum age to which a pension recipient might potentially live;

$A=$ age of the pension recipient at time the pension is purchased;

$r$ = discount rate applicable to the pension stream to be discounted.

Part of this fee is charged up front and disclosed. Denote the disclosed component of the fee as $F$. However, there is a second undisclosed component of the fee. The undisclosed fee is the value at the time of the pensioner's death of the accumulated value of the assets initially purchased by the institution (for $C-F$ ) plus the income thereon less the amounts distributed as pension payments through time. The PV of the future undisclosed fee charged at the time of the pensioner's death is simply Fee $-F$.

The undisclosed fee at the time of death can be negative if the pensioner lives a sufficiently long time. A negative fee means that the accumulated pension payments made by the time of the pensioner's death exceed the value of $C-F$ aggregated with interest earnings. The practice of not disclosing the likelihood of this second fee and its potential size can only be justified if its present value can reasonably be taken to be zero. 
Table 3: Pension Payments, Undisclosed Fees and Present Values

\begin{tabular}{|c|c|c|c|c|c|c|c|c|}
\hline (1) & (2) & (3) & (4) & (5) & (6) & (7) & (8) & (9) \\
\hline Age & $\begin{array}{l}\text { Balance at } \\
\text { financial } \\
\text { institution prior } \\
\text { to pension } \\
\text { payment at a } \\
\text { given age }= \\
\text { lagged value of } \\
(4) \times 1.06\end{array}$ & Pension & $\begin{array}{c}\text { Undisclosed fee } \\
\text { if die at a given } \\
\text { age } \\
=(2)-(3)\end{array}$ & $\begin{array}{c}\text { PV of } \\
\text { undisclosed fee } \\
\text { if die at a given } \\
\text { age }=(4) \\
\text { discounted back } \\
\text { to age } 60 \text { at } 6 \% \\
\text { p.a. }\end{array}$ & $\begin{array}{l}\text { PV pension } \\
\text { income if live to } \\
\text { a given age = } \\
\text { sum of } \\
\text { discounted } \\
\text { values in (3) up } \\
\text { through death } \\
\text { with discounting } \\
\text { at } 6 \%\end{array}$ & $\begin{array}{l}\text { Probability of } \\
\text { death at each } \\
\text { particular age } \\
\text { given a female } \\
\text { is currently } \\
\text { aged } 60 \text { based } \\
\text { on current } \\
\text { mortality tables }\end{array}$ & $\begin{array}{c}\text { PV of } \\
\text { undisclosed fee } \\
\text { if die after } \\
\text { reaching a } \\
\text { given age } \times \\
\text { Probability of } \\
\text { death at that } \\
\text { age }=(5) \times(7)\end{array}$ & $\begin{array}{l}\mathrm{PV} \text { all future } \\
\text { pension income } \\
\text { received if die } \\
\text { after reaching a } \\
\text { given age } \times \\
\text { Probability of } \\
\text { death at that } \\
\text { age }=(6) \times(7)\end{array}$ \\
\hline 60 & & & $\$ 500000$ & $\$ 500000$ & $\$ 0$ & 0.005100 & $\$ 2550$ & $\$ 0$ \\
\hline 61 & $\$ 530000$ & $\$ 21000$ & $\$ 509000$ & $\$ 480189$ & $\$ 19811$ & 0.005537 & $\$ 2659$ & $\$ 110$ \\
\hline 62 & $\$ 539540$ & $\$ 21630$ & $\$ 517910$ & $\$ 460938$ & $\$ 39062$ & 0.006005 & $\$ 2768$ & $\$ 235$ \\
\hline 63 & $\$ 548985$ & $\$ 22279$ & $\$ 526706$ & $\$ 442232$ & $\$ 57768$ & 0.006506 & $\$ 2877$ & $\$ 376$ \\
\hline 64 & $\$ 558308$ & $\$ 22947$ & $\$ 535361$ & $\$ 424056$ & $\$ 75944$ & 0.007049 & $\$ 2989$ & $\$ 535$ \\
\hline 65 & $\$ 567482$ & $\$ 23636$ & $\$ 543847$ & $\$ 406394$ & $\$ 93606$ & 0.007656 & $\$ 3111$ & $\$ 717$ \\
\hline 70 & $\$ 609972$ & $\$ 27400$ & $\$ 582572$ & $\$ 325305$ & $\$ 174695$ & 0.012085 & $\$ 3931$ & $\$ 2111$ \\
\hline 75 & $\$ 643030$ & $\$ 31764$ & $\$ 611266$ & $\$ 255060$ & $\$ 244940$ & 0.019272 & $\$ 4915$ & $\$ 4720$ \\
\hline 80 & $\$ 659674$ & $\$ 36824$ & $\$ 622851$ & $\$ 194208$ & $\$ 305792$ & 0.029685 & $\$ 5765$ & $\$ 9077$ \\
\hline 85 & $\$ 649959$ & $\$ 42689$ & $\$ 607270$ & $\$ 141493$ & $\$ 358507$ & 0.042153 & $\$ 5964$ & $\$ 15112$ \\
\hline 90 & $\$ 599873$ & $\$ 49488$ & $\$ 550385$ & $\$ 95828$ & $\$ 404172$ & 0.042899 & $\$ 4111$ & $\$ 17338$ \\
\hline 95 & $\$ 489856$ & $\$ 57370$ & $\$ 432486$ & $\$ 56269$ & $\$ 443731$ & 0.027907 & $\$ 1570$ & $\$ 12383$ \\
\hline 100 & $\$ 292790$ & $\$ 66508$ & $\$ 226283$ & $\$ 22000$ & $\$ 478000$ & 0.011372 & $\$ 250$ & $\$ 5436$ \\
\hline 105 & $-\$ 28705$ & $\$ 77100$ & $-\$ 105805$ & $-\$ 7687$ & $\$ 507687$ & 0.003077 & $-\$ 24$ & $\$ 1562$ \\
\hline 110 & $-\$ 525916$ & $\$ 89381$ & $-\$ 615297$ & $-\$ 33403$ & $\$ 533403$ & 0.001704 & $-\$ 57$ & $\$ 909$ \\
\hline
\end{tabular}


Table 3 shows the analysis underlying the determination of the present value of the undisclosed fee given a set of parameter values consistent with those available in the market. To illustrate the methodology, the values for each year are given for ages 60 to 65 years, then at five-yearly intervals to age 110 years.

A 60 year-old female is assumed to invest $\$ 500,000$ in an indexed life pension. Assume initially for simplicity that $F=\$ 0$. (This assumption will be relaxed later.) The income recipient is promised a lifetime of annual payments that grow by 3 per cent each year. The first payment is $\$ 21,000$ and will be received at the end of the first year when the pensioner is aged 61. The promised annual pension is shown in column (3). Assume, also for simplicity, that pensioners die immediately after a birthday and receive the pension amount due on their birthday. (The actual timing of death within a year has no effect on the present values calculated so long as our pensioner receives a payment on her birthday only if she is alive that day.) If our would-be pensioner dies before turning 61, she receives nothing and the $\$ 500,000$ is retained by the financial institution. If she lives only until her $61^{\text {st }}$ birthday she will receive the $\$ 21,000$ promised at that date, but the rest of $C-F$ plus the earnings thereon is forfeited to the financial institution. It is this forfeited amount that is the undisclosed fee.

The financial institution is assumed to be able to earn 6.0 per cent each year on its investments. The institution will have assets of $\$ 500,000 \times 1.06=\$ 530,000$ immediately before paying the pension due at age 61 - see column (2). After paying the $\$ 21,000$ pension due, the institution will have a balance of $\$ 509,000$ see column (4). If the pensioner dies immediately after receiving this first payment, the balance of $\$ 509,000$ is forfeit to the institution and constitutes the undisclosed fee. The PV of this potential future undisclosed fee is $\frac{\$ 509,000}{1.06}=\$ 480,189-$ see column (5).

Column (5) shows the PV of the future undisclosed fees associated with death at each possible age. Column (6) shows the PV of the future pension income received until each given age. For example, a would-be pensioner who lives for only one year will receive a future pension income with a present value of $\frac{\$ 21,000}{1.06}=\$ 19,811$. A would-be pensioner who lives for two years will receive a future pension income with a present value of $\frac{\$ 21,000}{1.06}+\frac{\$ 21,000 \times 1.03}{1.06^{2}}=$ $\$ 39,062$. Note that columns (5) and (6) always sum to the initial investment of $\$ 500,000$. For example, consider death at age 61 : $\$ 480,189+\$ 19,811=$ $\$ 500,000$.

Column (7) shows the probability of death at a given age for an Australian female currently aged 60 as per the most recent life tables computed in 2002. These life tables do not contain the age distribution of deaths that occur after age 110. All deaths occurring after age 110 have been assumed to occur at age 110 . The effect of this assumption is to bias upwards trivially the estimate of the PV of the future undisclosed fee. This bias is discussed below. 
Column (8) gives the PV of the expected future undisclosed fee at each future birthday - the product of the PV of the future undisclosed fee if the pensioner were to die after reaching a particular age and the probability that the pensioner will actually die at that age. Column (9) shows the product of the PV of the future pension payments received up through each given age and the probability that the pensioner will actually die at that age.

Summing column (8) over the potential lifespan gives the PV of the expected future undisclosed fee. For the parameter values in this example, the PV of the expected future undisclosed fee is $\$ 155,695$. Summing column (9) over the potential span gives the PV of the expected future pension income to be received. This amount is $\$ 344,305$ - far less than the cost of the pension. Note that the $\$ 500,000$ paid to the financial institution is simply the sum of the PV of what the pensioner receives and the PV of the undisclosed fees the institution retains; that is, $\$ 500,000=\$ 344,305+\$ 155,695$.

Note that only if a pensioner lives to 104 or beyond will the pension distributions from her account exhaust the accumulated balance therein; i.e., only if a pensioner lives to 104 or beyond will the undisclosed fee in column (4) become negative meaning that the supplier will have to start using the supplier's own capital to pay the promised pension. Based on current mortality tables, the life expectancy of a 60 year old female is 84.9 years - 19.1 years short of the lifespan that will lead to a loss for the supplier.

\section{Costs and disclosure}

All of the PDSs state that the income payments are net of all expenses. The expenses which the suppliers incur include initial and annual commissions, and investment, administration and distribution costs. The largest of these individual costs is highly likely to be the initial commissions paid to financial advisers. (The PDSs state that these commissions may be deducted even where a financial adviser is not consulted.) For example, 'Where other [than financial advisers] sales methods are used, lower charges will not necessarily result' (Company C PDS:4). What then are potential clients informed about these expenses?

The PDSs for these products contain specific information on fees and charges:

Included in the costs and expenses that we take into account when determining the income that we can offer is the remuneration that is generally payable to a financial adviser. Initial commission (including bonuses and GST) of up to 4.125 per cent of the investment is paid to your financial adviser. We may also offer incentives to your financial adviser which are paid by [A]. (Company A)

Once you decide to buy the plan, your Financial Planner is entitled to earn a commission as follows: ... Up to 3.96 per cent of your purchase price. Individual Financial Planners ... may also qualify for other benefits. The value of the benefits they receive depends on the value of 
the products they sell and on average is no more than 0.3 per cent of the investment made. (Company B)

For a lifetime annuity your financial adviser may receive a maximum of 3.3 per cent of your purchase price. ... Your adviser may receive ongoing commission of up to 0.275 per cent per annum of the purchase price. ... We may make payments to dealer groups based on commercial arrangements. ... These payments are not charged to you ...'. (Company C)

From these disclosures, it is apparent that between $\$ 16,500$ and $\$ 20,625$ would be paid out initially to the client's financial adviser if she employed one. No other fees or charges are quantified in the PDSs. The next section examines possible rationalisations of the apparently high undisclosed fees.

\section{Possible Rationalisations of the Undisclosed Fees}

There is a number of possible explanations of the high undisclosed fees on indexed pensions. These include:

- Suppliers cannot be sure of, and hence cannot lock in, interest rates beyond 10 years (Australian Government bonds have maturities of 10 years or less);

- Suppliers may need to use owners' equity to honour the contracts if either their investments perform poorly or the pensioner lives for a sufficiently long time;

- $\quad$ Suppliers face a potential adverse selection problem in that their clients may turn out to be healthier than the average reflected in standard mortality tables;

- $\quad$ Suppliers can not be certain that all their 110-year old clients will actually die within one year as is assumed in the analysis;

- More generally, suppliers face the risk that the current mortality tables may underestimate future life spans given (i) improvements in health (increased exercise, healthier foods, less smoking) and (ii) advances in the medical sciences; and

- $\quad$ Suppliers must bear the administrative costs of the product.

\section{Reinvestment rate uncertainty}

Suppliers may observe that current 10-year market rates may well be around six per cent, but no one knows what interest rates will be when the accumulated remaining assets must be reinvested to provide the pension payments due to the pensioner beyond her $70^{\text {th }}$ birthday. The worst case interest-rate scenario from the point of view of the financial institution is that after 10 years interest rates fall to the levels currently observed in Japan; that is, effectively to zero per cent. The institution is still committed to pay annual pension amounts that are growing by three per cent each year. 
The analysis was repeated, but this time assuming that interest rates fall to and remain at zero per cent per annum after our pensioner turns 70 years of age. The PV of the future expected undisclosed fee is now almost zero (equal to only \$2,098). However, a belief that interest rates are certain to fall to zero is not credible. Any possibility of a future interest rate above zero means that the PV of the future expected undisclosed fee exceeds \$2,098.

The risk of needing to use the supplier's own capital to honour the contract

Should the financial institution invest in risky assets, it is exposed to the risk that it may have to use owner's equity to meet the pension commitments should its investments perform poorly. On the other hand, if those investments do well, the institution retains the gains. As the fee is the difference between the amount paid for the pension and the present value of the expected pension payments, it is unaffected by the institution's investment policy provided the institution always meets its commitments. Discounting the promised pension at the risk-free rate is appropriate provided the financial institution always meets its commitments.

If there is a chance that the institution will default on the promised pension, the fee being paid is greater still. The financial institution keeps the upside but may pass the downside risk back to the pensioner by defaulting. If the pension is not default-free, then the discount rate appropriate to the determination of the PV of the pension payments exceeds the risk-free rate, and hence the PV of the pension (the fee) is lower (higher) than that calculated above.

\section{Adverse selection}

To get a sense of the potential size of the adverse selection problem, imagine that someone at age 60 knows she has a higher than normal chance of living to 104 or beyond. Based on current life tables, the probability of the average 60 year old female living to age 104 or beyond is only 1.4757 per cent. Our healthy female is assumed to know that she has a probability of death at any age prior to 104 that is a fixed fraction of the percentages in Table 3. Similarly, her chance of death at 104 or greater is assumed to be a fixed multiple of the percentages in Table 3. (The fact that death is eventually certain links the fraction and the multiple by a rather grim adding up constraint.)

The question is how much higher than 1.4757 per cent per cent must the probability of living beyond 103 be, for it to be optimal for a 60-year old female to purchase the product; that is, how large would the multiple have to be before it would be optimal to buy the lifetime pension? The answer is that only if one were more than 62 times as likely as the average 60 year old female to live beyond 103 would it be optimal to purchase this life-time pension. Current medical knowledge is such that there is simply no possibility of indicators accurately signalling to a person considering the purchase of this product that her chance of living beyond 103 is more than 62 times the average woman's chance of reaching such a great age. It seems that the adverse selection problem will be small. Buyers may know that they have not been smokers, are not overweight and 
exercise regularly so may then be more attracted to the product, but they surely could not feel confident that their chance of surviving beyond age 103 is 62 times the average chance.

\section{The assumption that no-one lives beyond 110}

According to current mortality tables, only 0.1661 per cent of 60 year old females will live beyond 110 years. The previous analysis assumes all these individuals die before reaching their 111th birthday. The analysis was repeated but with a changed assumption about mortality rates: everyone who lives to be 110 is now assumed to live for another 10 full years; that is, to live until age 120. The PV of the expected future pension payments in this altered scenario is $\$ 344,376$ and the PV of the expected future undisclosed fee is $\$ 155,624$ - only $\$ 71$ less than the initial estimate of $\$ 155,695$.

\section{Current mortality tables may underestimate future life spans}

While pandemics may decrease future life spans, all recent evidence is of ever increasing life spans. To account for this possibility, the analysis was repeated with a further change to the assumption about mortality rates. Again everyone who lives to 110 is assumed to live to 120 . Further, the probability of death at any age prior to 86 is assumed to be only half that reflected in current mortality tables. (The expected total lifespan of a 60 year old female is 84.9 years given current mortality tables.) The probability of death at age 86 or later must be increased. The increased rate is assumed to be a constant multiple of the probability given in current mortality tables. That multiple must be 1.46553 . This change in mortality rates implies a 3.8 year increase in the expected total lifespan of a 60 year old woman - from 84.9 to 88.7 years. The PV of the undisclosed fee is still high, namely $\$ 117,389$.

\section{Suppliers' administrative costs}

One indirect way to see that future administrative costs are unlikely to fully explain the difference between the cost of the pension and the present value of the expected future pension income is to examine the structure of a similar product offered by a viable non-profit industry fund, such as Unisuper, the superannuation fund of university staff. Unisuper offers a pension indexed to CPI; thus, the members as a group carry the risk of just what inflation will be each year. Unisuper's quote for this client is $\$ 28,090$ per annum, paid monthly. At an interest rate of 6.0 per cent, this payment is equivalent to $\$ 28,875$ at the end of the first year. Unisuper discloses a \$140 annual member fee, indexed in line with inflation, and deducted at the start of the pension (Unisuper PDS). Assuming a 3 per cent inflation rate and a 6 per cent discount rate, the PV of this fee stream will only be $\$ 3,833$ even if the pensioner lives to be 120 and therefore pays fees for the next 60 years. (Cross-subsidisation of products by Unisuper is a possibility, but Unisuper does charge higher fees for the more complex allocated pension 
product.) Comparing Unisuper's quote to the quote supplied by supplier B, we see that despite its own administrative costs, Unisuper is able to promise a CPIindexed pension that starts at a level nearly $\$ 8,000$ per annum higher than supplier B offers.

Still the preceding numerical analysis assumes that the supplier earns a 6 per cent return and the discount rate is also 6 per cent. What happens if some percentage of the assets is consumed in administrative costs each year and the supplier earns a net return of less than 6 per cent? We continue with the assumption of improved mortality and an average life span of 88.7 years for women who reach 60. If the supplier bears administrative costs of 1 per cent per annum, the PV of the undisclosed fee falls to $\$ 55,532$. (Whether it is an undisclosed administrative cost or an undisclosed fee is immaterial to buyers the break up is, though, of interest to those seeking to understand the economics of this industry.) Only if the supplier bears an administrative cost of 2.4 per cent per annum is the PV of the undisclosed fee equal to zero. Unisuper's quotes suggest that Unisuper at least does not operate with such a high administrative cost structure.

\section{Policy Issues and Conclusion}

The decision to purchase a lifetime indexed pension involves three steps - firstly, deciding to purchase a product of that class; secondly, deciding on the design of the product; and thirdly, deciding which particular product among those offered in the market gives the best value for the funds expended. The third step is the easiest about which to make a decision. For a cost of $\$ 500,000$ initially, company A will pay \$5,110 quarterly, indexed annually at three per cent, for the remaining lifetime and company $\mathrm{C}$ will pay $\$ 5,674$ quarterly under the same conditions. Company B will pay $\$ 5,277$ quarterly, indexed to CPI annually, also for the remaining lifetime.

The decision between products $\mathrm{A}$ and $\mathrm{C}$ is easy. $\mathrm{C}$ gives better value for money. Both suppliers are large seemingly stable firms, so default risk is likely to be low. Clients considering the product design with a pre-selected absolute value for inflation adjustment, such as three per cent, must realise that they carry the risk that inflation will not be experienced at that selected rate. On the other hand, Product B, being indexed to inflation, extinguishes that risk. The client would have to consider whether the nearly $\$ 400$ difference in receipts each quarter in the first year (with a varying margin in later years depending on inflation) is an appropriate cost to pay to pass the inflationary risk back to the supplier. The basis of this decision is the risk tolerance of the client. If she is very risk averse, she will opt for the 'dearer' CPI option; if less risk averse, then she will assume the risk inherent in purchasing a pension with the fixed three per cent uplift factor.

The design of the product is also relatively easy. Each client has a particular set of personal and financial circumstances. In each individual case, one product design will clearly be more appropriate and, following adequate analyses, the decision should be made to obtain quotes on that set of product characteristics. 
The first step in the decision-making process, that is, whether this class of product is appropriate and yields value for money, is the most difficult for many people. This is the part of the decision that needs full disclosure and where many people need help and advice, because they lack adequate financial skills. While financial literacy among Australians has been found to be 'reasonable' when measured in very basic terms (ANZ Banking Group, 2003), many surveys have found more sophisticated financial skills to be deficient. For example, the ANZ Banking Group (2003:7) report itself found 63 per cent of respondents had not estimated the necessary savings goal to fund their retirements, a very basic requirement in the retirement-funding planning exercise. In addition, Beal and Delpachitra (2004) found only 20.1 per cent of a predominantly tertiary-educated sample of people could correctly convert a target annual retirement income to a lump sum necessary at retirement. The implications of these findings are that people generally lack more advanced financial skills and it seems fair to conclude that many are unlikely to be able to conduct appropriate financial analyses without a great deal of assistance.

If the disclosure documentation for these products included a statement incorporating the following five points, disclosure would be clear, concise, informative and verifiable.

- The discounted value of the expected future pension payments to be received by you is $\$ . .$. ;

- The discount rate used in the calculations is the current yield of 10-year Australian Government bonds;

- The expectation of future pension payments is based on the Australian Government Actuary's most recent tables of mortality rates;

- In the future, the typical life span may either increase or decrease. Medical advances may lead to an increase in average life spans and current mortality rates may not be representative of the future;

- If you live until you reach age ..., the discounted value of the pension payments you will receive will exceed the purchase price of the pension. If you die before reaching that age, the discounted value of the pension payments you will have received over your life will be less than the purchase price of the pension.

Fixed term products could and should also make minimal disclosures of an analogous form.

- The discounted value of the future pension payments to be received by you is $\$ \ldots$;

- The discount rate used in the calculations is the current yield of 10-year Australian Government bonds. 
Potential clients, either with their current level of knowledge or following adequate explanation, could then decide on a more informed basis than is currently the case whether lifetime products were appropriate for their circumstances.

The establishment of this degree of disclosure would almost certainly reduce the current demand for these products but, on the other hand, has the potential to later deepen the market for this type of product as potential buyers come to contemplate the range of their potential life spans. The Treasurer's post-20 September 2004 policy change to reduce the assets-test exemption to 50 per cent alters the market environment for lifetime annuities. While some retirees will be attracted to the new class of term allocated pensions (TAPs), there will still be retirees who are most comfortable with a class of products which pass many forms of risk to the suppliers. Possibly the sales of guaranteed income-stream products will decrease but, while this product is offered in the marketplace, more disclosure is desirable.

\section{References}

ANZ Banking Group (2003), ANZ Survey of Adult Financial Literacy in Australia - Final Report, ANZ, Melbourne.

Australian Government Actuary, Australian Life Tables 2000-02.

Australian Prudential Regulation Authority (2005), Superannuation Trends, September Quarter 2004, APRA, Sydney.

Beal, D. and S. Delpachitra (2004), 'Community Understanding of Superannuation', Agenda, 11(2):127-142.

Foster, R. (1996), Australian Economic Statistics 1949-50 to 1994-95, Reserve Bank of Australia, Sydney.

Investment and Financial Services Association Ltd (2004), 'Growth Pensions', available at: www.ifsa.com.au/IFSAWeb (accessed 13 July 2004).

Kelly, S. and A. Harding (2004), 'Funding the Retirement of Baby Boomers', Agenda 11(2):99-112.

Treasurer [The Hon. P. Costello] (2004), 'A More Flexible and Adaptable Retirement Income System', Statement released by Treasurer, available at: http://demographics.treasury.gov.au/content/_download/flexible_retirement_income_syste m/flexible_retirement_income_system_no_cover.pdf (accessed 21 July 2004).

The authors gratefully acknowledge the helpful suggestions of referees and an editor. 